
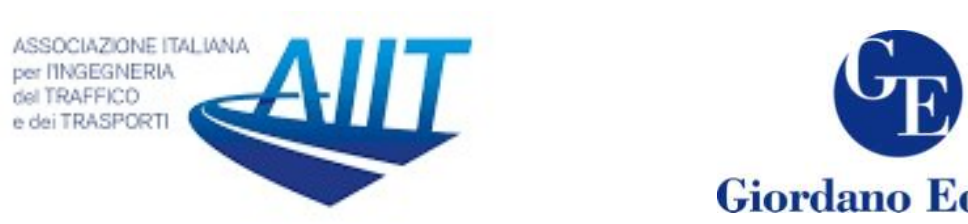

Giordano Editore

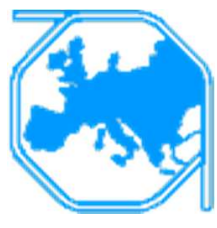

\title{
Accident Analysis of Bus Rapid Transit System: Before and after construction
}

\author{
Amir Izadi ${ }^{1}$, Faramarz Jamshidpour ${ }^{1}$, Daniel Safari ${ }^{2}$, Vahid Najafi \\ Moghaddam Gilani \\ ${ }^{1}$ Department of Civil Engineering, Shomal University, Amol, Iran. \\ ${ }^{2}$ School of Civil Engineering, Iran University of Science and Technology (IUST), Tehran, Iran
}

\begin{abstract}
Among the various transportation systems, public transportation, especially Bus Rapid Transit (BRT), has a significant role in urban transport and has the mission of transfer of passengers and reducing travel time. In addition to these advantages, the weak and non-standard design and implementation of BRT lines result in an escalation of accidents and inefficiency. Therefore, the aim of this study is to investigate the influential factors of the severity of BRT lines accidents before and after their construction. For this purpose, the accident data of Rasht BRT line 1 over the years of 2016 (before the construction of the BRT), 2017 and 2018 (after the construction of the BRT) have been analysed. The results showed that the construction of BRT has brought about 36 and 43 per cent reduction of accidents in 2017 and 2018, respectively, in comparison with 2016, and has given rise to the emergence of new accidents, such as collision with separator fence.
\end{abstract}

Keywords: Accidents, BRT Line, Bus, Road safety index, Construction

\section{Introduction}

Nowadays, according to the rapid growth of urbanisation, cities are considered to be the most important centres for the attraction of suburban and rural populations. The continuation of this urbanisation increases the population density of cities more and more. Moreover, traffic is one of the problems that the residents and authorities of large cities are struggling with it. It's been a long time that the issue of public transportation systems has gone beyond engineering and become a social and economic issue that can have different consequences for a community (Bargegol et al., 2017; Raju et al., 2016).

The public transportation systems, the most important of which are buses and subway, play a very significant role in the daily commuting of travellers in the cities. One of the many types of public transportation systems is Bus Rapid Transit (BRT). This system includes many benefits that directly and indirectly affect the quality of everyday life of the people. One of the essential advantages of this system is to reduce the losses and injuries caused by passenger car accidents (Vecino-Ortiz \& Hyder, 2015). Using of BRT also causes less stress compared to driving in heavy traffic and its waste of time to find suitable parking space (Scorcia \& Munoz-Raskin, 2019). However, despite a general 
reduction in accidents, it is likely to result in accidents with new causes or an increase of specific accidents which do not occur under the absence of BRT system conditions.

In many cities in Iran, the bus transit system has not been efficient so far. Many management practices, such as allocation of special lines for the buses, bus schedule planning, etc., which are needed to improve the system's efficiency, have not been adequately considered. In contrast, if the potential capacity of the bus system is utilised correctly, it could cover up to half of the urban public transportation demand, which would result in using fewer people of personal cars. However, recently, the government has initiated a new project called the BRT to enhance the quality of bus transit throughout the country. Each BRT system in one city has multiple routes. One of these BRT routes is Rasht BRT line 1. Some problems of this line include the entering of taxis and other vehicles into the special line of the BRT, the lack of continuity of the route at intersections, the low number of bus fleets. All of these have made the study of this route more important.

Many studies have been carried out on accidents in urban areas as well as bus special lines. These studies mainly predict the accident pattern of the BRT lines (Gómez \& Bocarejo, 2015; Yoon et al., 2017), accidents occurred due to the right of way violation of buses in intersections and urban streets (Goh et al., 2013; Song \& Noyce, 2018; Wenfang et al., 2018; Goh et al., 2014; Goh et al., 2014), and the safety of pedestrian and bicycle crossings at the intersection with bus special lines (Morency et al., 2018; SantosReyes \& Ávalos-Bravo, 2014). The width of the special lines of the bus also plays an important and noticeable role in the severity of accidents (Kim et al.,2012).

The high speed of the buses can also enhance the service level and capacity of the BRT system and differentiate it from other modes of transportation. But, at the same time, increase the number of accidents at the conflict points (Bocarejo et al., 2012; Calvo, 2017). The main aim of this study is to suggest appropriate strategies to reduce accidents and increase the convenience of citizens and passenger safety. In order to reach this goal, accident statistics of Imam Street in Rasht before and after the construction of the BRT route are analysed by several methods, and the factors which could be troublesome are identified.

\section{Methodology}

After the construction of the Rasht BRT line 1, the route encountered new accidents, including accidents with fences and increased accidents at intersection points. Therefore, in this paper, it was decided to investigate the parameters affecting the severity of accidents of the BRT route after construction. Hence, by collecting accident data in 2016 (before construction) and 2017 and 2018 (after construction), the effective variables were analysed. Analyses such as Friedman, Factor analysis, and Logit Model were used. Also, a new model for identifying dangerous points was developed by combining and weighting RSI, EPDO and SI indexes according to traffic experts' opinions. The reason for using different methods is to consider different aspects of accident analysis in this study because each method analyses accident information using its unique algorithms and relationships. The Friedman method deals with the ranking of the influential parameters, and the factor method explores the most effective factors on accidents. The logit model is a model that can be built to determine the occurrence probability of the parameters involved in the accidents (Bargegol et al.,2016; Gilani et al., 2017). Each of these methods is described in the following. Also, in Figure (1), the study process and the methods of analysis and modelling are shown. 


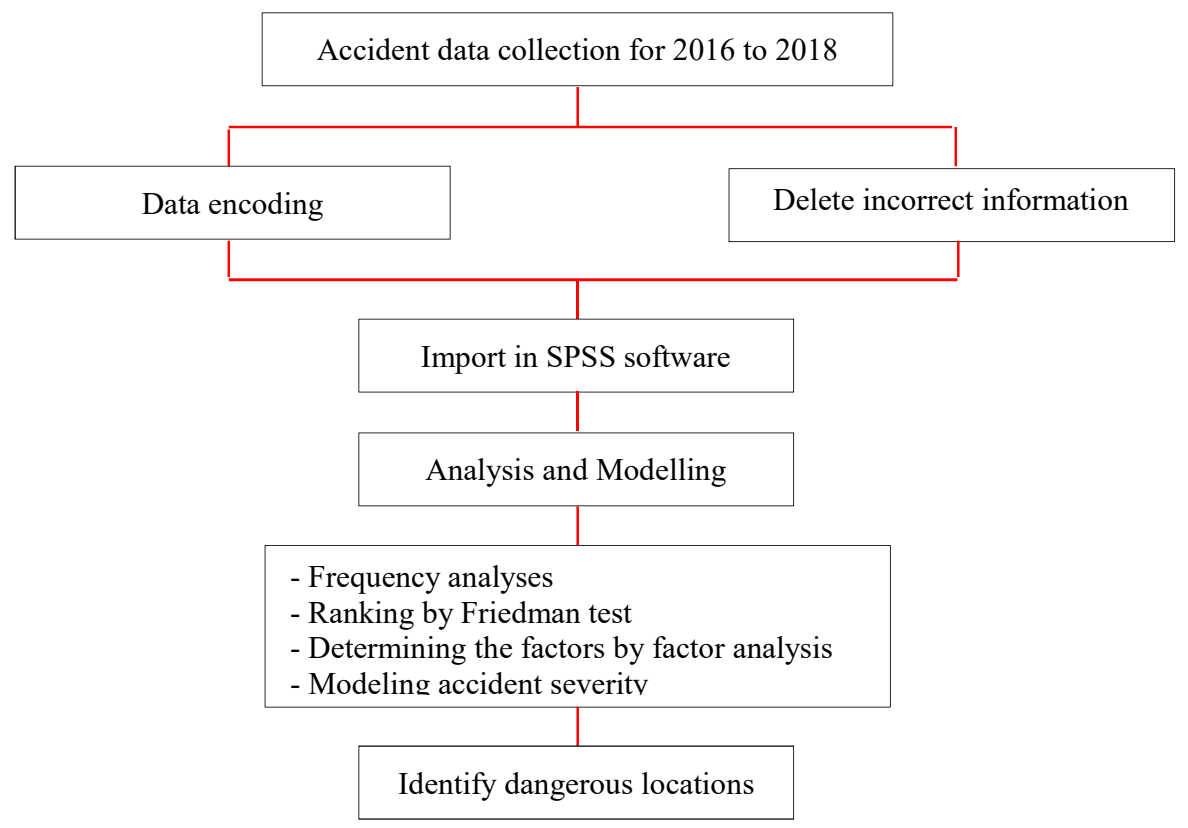

Figure 1: Flowchart of the present study

\subsection{Multiple Logit Regression}

The logit regression method is a mathematical method used to describe the relationship between multiple variables $\mathrm{x}$ and a two-valued dependent variable. A function that is used in this method is an S-shaped function called a logit function, which can also be applied in multi-valued problems by expanding. As it referred, the logit regression can be utilised to define the variable $\mathrm{Y}$ as the multi-valued (Bargegol et al.,2016). In the simplest case, we can consider $\mathrm{P}(\mathrm{Y}=\mathrm{i})$ as a linear function of $\mathrm{xI}(\mathrm{Pi}=\mathrm{xi} \beta)$, where $\beta$ is the vector of regression coefficients. The consideration about this equation is that the probability $\mathrm{Pi}$ in the left side of the equation should be between zero and one, but the linear vector product xi $\beta$ in the right side including the all real numbers. A simple method for solving this problem is to use the probability transfer function to remove the distances limits and model the transferred function as a linear function of the parameters. This conversion occurs in two steps. First, the Pi probability changes to the chance of success, according to equation 1:

$$
O d d S=\frac{p_{i}}{1-P_{i}}
$$

In the second step, the logarithm is taken of the equation mentioned above to obtain the logit or success chance logarithm (equation 2):

$$
\operatorname{Logit}\left(p_{i}\right)=\log \frac{P_{i}}{1-p_{i}}
$$

The results are quite similar. The reverse transfer function, sometimes called antilogic, is applied to calculate probability in terms of logit (equation 3):

$$
\operatorname{Logit}^{-1}\left(Z_{i}\right)=\frac{e^{z_{i}}}{1+e^{z_{i}}}
$$

Therefore, the logit is a transfer function that associates the probabilities in the interval $(0,1)$ to all real numbers. The negative logit represents less than $50 \%$ probability, and positive logit represents more than $50 \%$ probability. Thus, the logit model is a general 
linear model that has a logit transfer function. In other words, logit of Pi probability, instead of the probability, follow the linear model (Bargegol et al., 2017).

\subsection{Factor analysis}

The factor analysis method is used to find out the underlying variables of a phenomenon or summarise a set of data. The primary data for factor analysis is the matrix of correlation between variables. Factor analysis does not have predetermined dependent variables. Uses the factor analysis can be divided into two general categories: exploratory purposes and confirmatory purposes. If there is no speculation about the structure of the dimensions relationships, exploratory factor analysis is used. Otherwise, the confirmatory factor analysis needs to be used (Thompson, 2004). In exploratory factor analysis, the researcher seeks to investigate empirical data to discover and identify the indices as well as the relationships between them. There is no pre-defined model here. In other words, exploratory analysis, in addition to its exploratory or suggested value can be structure maker, modeller, or hypothesis creator.

\subsection{Friedman test}

The Friedman test is one of the statistical tests used to compare several groups and, ranks groups by means of average whether these groups can be of one community or not. This test is a non-parametric corresponding of the $\mathrm{F}$ test and is usually used in ranking scales rather than the F test (Chatfield \& Mander, 2009). In the F test, there should be homogeneity of variances that is less observed in ranking scales. The Friedman test is applied for the analysis of two-way variance (for non-parametric data) by a ranking method and also used to compare the average ranking of different groups.

\section{Case study}

The present study was conducted in Rasht, Iran. It is one of the metropolises of Iran and is the capital city of Guilan Province. This metropolis is considered to be the largest and most populous in northern Iran. (Behbahani et al., 2017; Bargegol et al., 2016). The studied BRT route, which named Line 1 or Imam, opened at the end of 2016 (December). It acts like a radius within a circular network structure that facilitates travel by creating a public transit line from the centre to the south side of Rasht city. It has five stations. The route continuation, which is from the centre to the north of the city, has not yet been reached on operational status. It is named line 2. The map of the studied BRT line and cross-sectional have been shown in Figure 2. Also, images of its route before and after BRT construction are shown in Figure 3. The route before the construction of BRT line had two crossing lanes with a parking lane on each side, after the construction, separator fences were added between two crossing lanes on each side to create a special lane without traffic just for the buses. Additionally, parking lanes have become crossing lanes, and at this time, parking is prohibited in the entire route. 


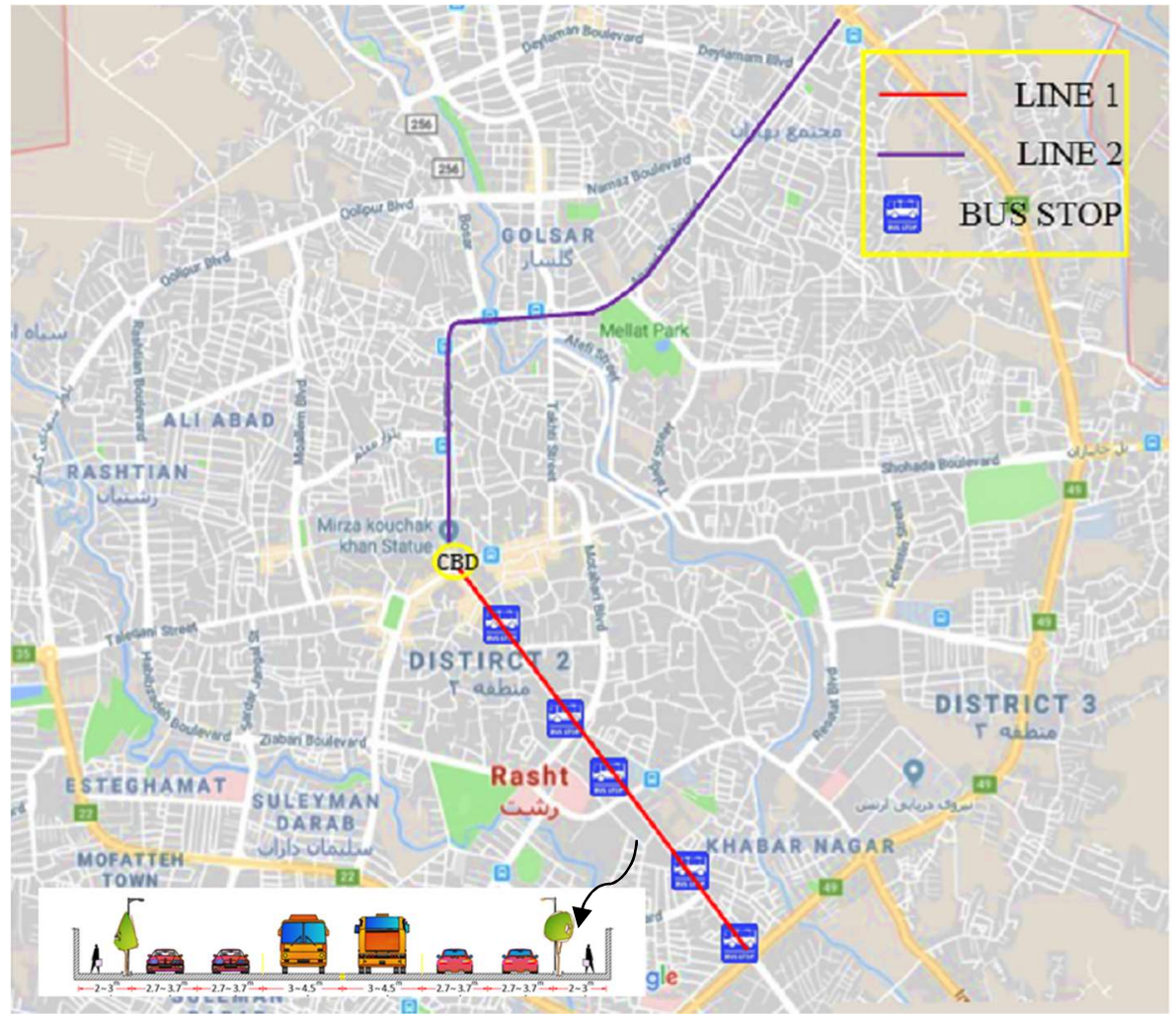

Figure 2: Rasht BRT lines 1 and 2
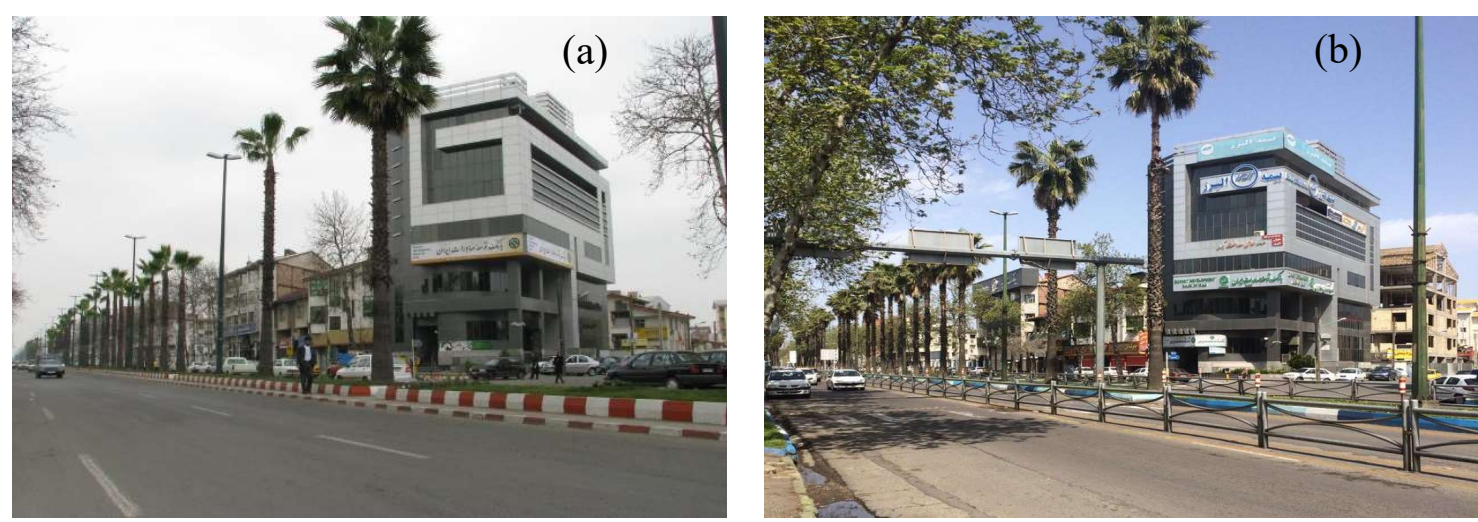

Figure 3: Images of the Rasht BRT route: a: before BRT, b: after BRT

\section{Analysis and Discussion}

In this section, all the accident data (both bus and other vehicle accident) of 2016 (before the construction of BRT) and then the years 2017 and 2018 (after the construction of BRT) were statistically, and frequency analysed. This data contains all accidents (not uniquely the bus accidents). Meanwhile, the factors influencing the severity of BRT line accidents were studied by factor analysis, Freidman, Logit model, as well as using different indices of RSI and EPDO.

\subsection{Frequency analysis of accident results}

By observing the frequencies of all accidents types, a significant reduction of $36 \%$ and $43 \%$ was indicated in 2017 and 2018, respectively compared to 2016. In other words, the implementation of BRT has given rise to the reduction of accidents in 2017 and 2018. As 
a result, the number of fatal accidents reached zero in 2018, and it is clear that the number of property damage accidents has increased after the construction of the BRT route, which may be due to the installation of separator fences or the reduction of the street width. In the following, the frequencies of other parameters which have effects on the BRT routes accidents have been presented. In Figure 4, the frequency of vehicle collisions with vehicles, pedestrians, separator fences and motorcycles (VPSM) are shown by year. In 2016, the number of collisions with the separator fence was zero. However, in 2017, after the BRT construction, it accounted for $11 \%$ of the total accident, which after the accustoming drivers to the BRT route, the number of accidents fell to $2 \%$ of total accidents. Another point is that collision with pedestrian has always had a large share of accidents.

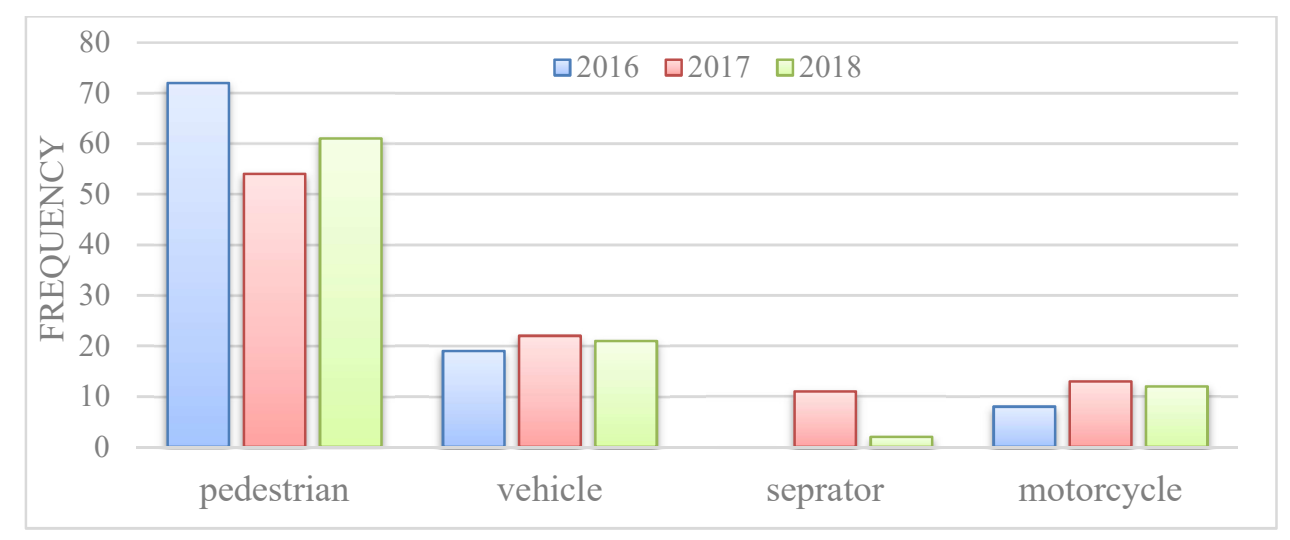

Figure 4: Accidents frequency according to the collision with VPSM by year

Figure 5 shows the main cause of accidents. According to it, the main cause of lack of attention has the most share of accidents in this route. After BRT implementation from 2016 to 2018, a significant increase in the accident due to failure to yield the right-of-way can be seen, which shows the necessity of giving drivers adequate training in the BRT right of way. Figure 6 shows the frequency of accidents by year according to road geometric characteristics. After the construction of BRT, the number of accidents at the intersections has increased. But those accidents which occurred along the route have decreased. The reason for the increase in accidents at intersections is the installation of the separator fences. Because before the fences were installed, the opposite traffic flows were not physically separated in any way, and drivers could make a U-TURN from everywhere of the route. However, after installing the fences, drivers who intended to make a U-TURN had to reach intersections, which led to increasing accidents at the intersections. 


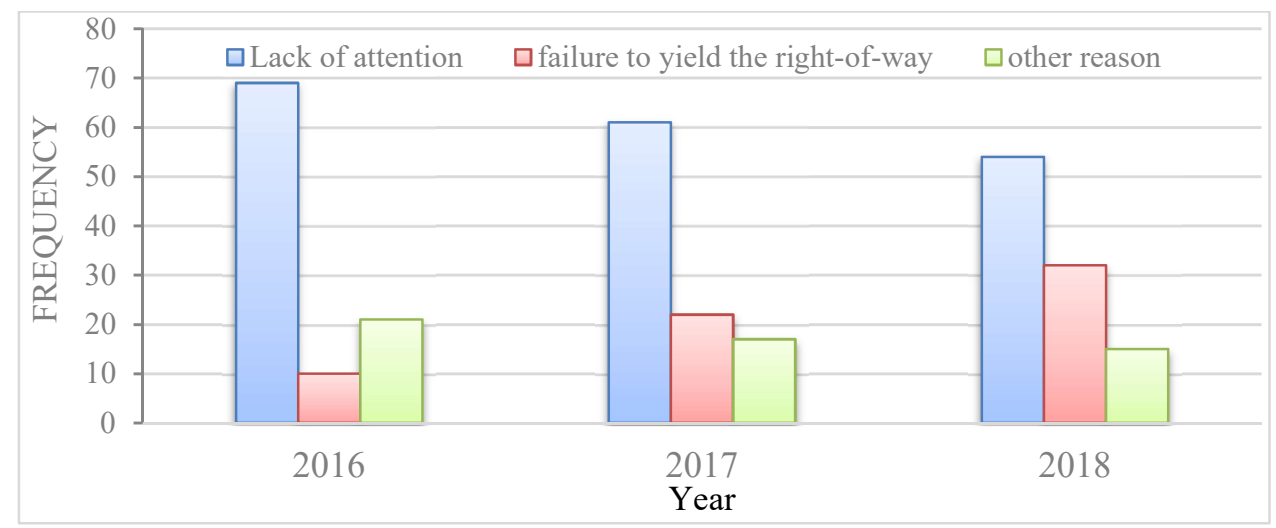

Figure 5: Accidents frequency according to the main cause by year

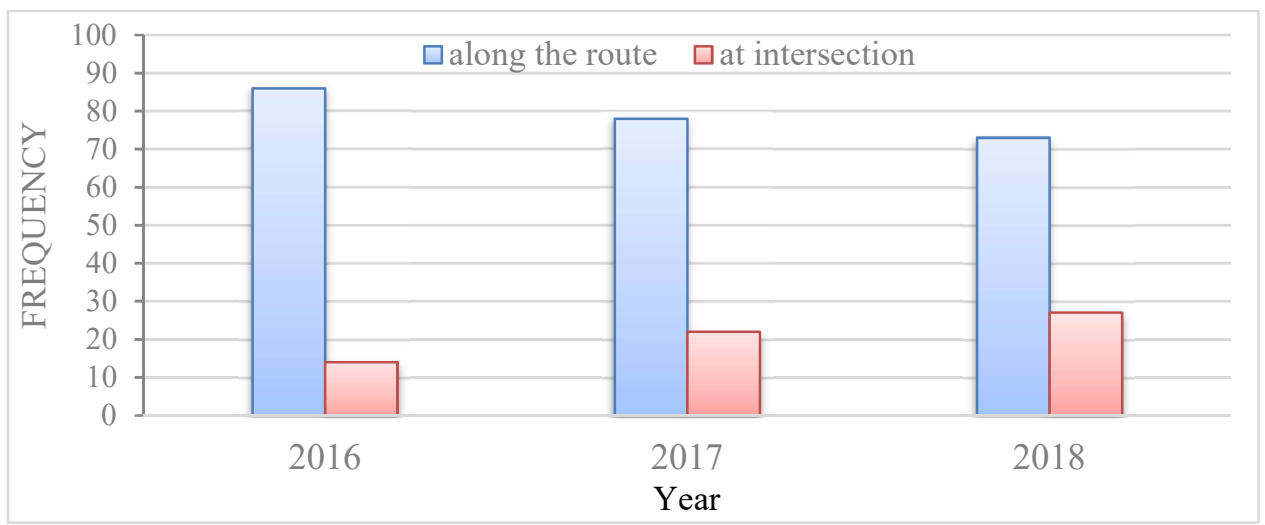

Figure 6: Accidents frequency according to road geometric characteristics by year

Figure 7 shows the lighting conditions at the accident times in the BRT of Imam rout, which, according to it, the accidents mainly occur during the day. This matter is due to the fact that most of the properties on Imam Street have commercial use as well as there are many private companies there; therefore, the volume of traffic and the tensions caused by driving are more during the day than noon or night. Hence, the number of accidents that occurred during the day is higher than other hours.

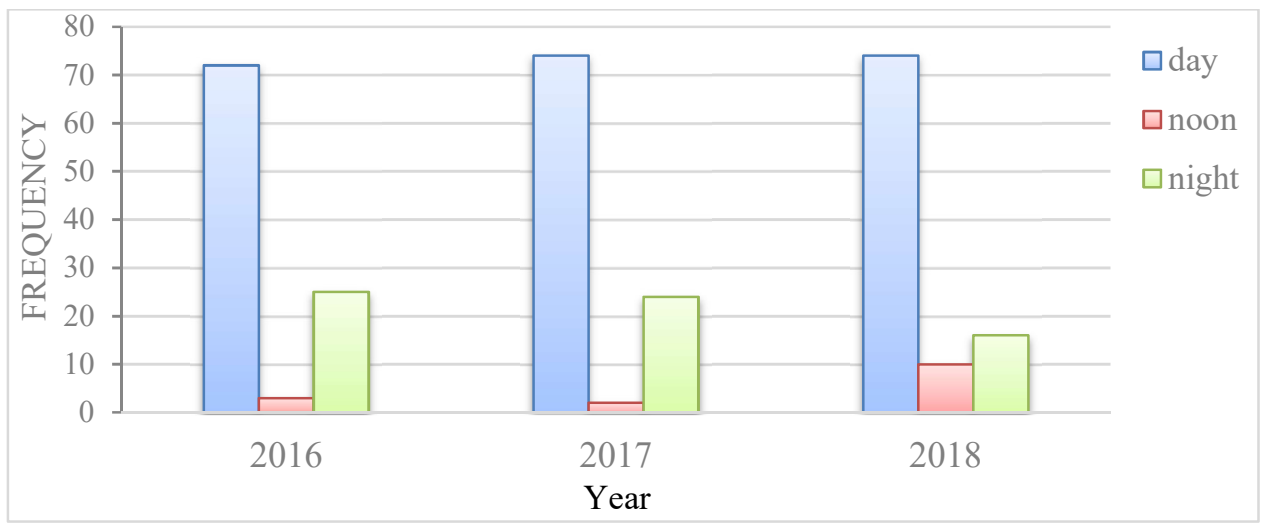

Figure 7: Accidents frequency according to lighting conditions by year 


\subsection{Friedman test results (determining the priority of factors)}

In this study, there were 13 independent variables for ranking the severity of accidents. Using the Friedman test, the ranking of each of these variables is evaluated. Table (1) shows the number of data, the value of chi-square statistic, degrees of freedom, and significance. Because the significance is less than $5 \%, \mathrm{H}_{0}$ is rejected, and the claim of the same rank (priority) of these 13 factors is not accepted. Table (2) is also a descriptive statistic that shows the mean ranks for each variable. Whatever the mean ranks of a variable are higher, the importance of that variable is greater.

Table 1: Statistical results of the Friedman test for accidents

\begin{tabular}{|c|c|c|c|}
\hline Year & Chi-square & Degree offreedom & Significance \\
\hline 2016 & 3164.821 & 12 & 0.00 \\
\hline 2017 & 1003.754 & 12 & 0.00 \\
\hline 2018 & 1910.445 & 12 & 0.00 \\
\hline
\end{tabular}

According to the rankings in Table (2), it can be concluded that the most important variables are geometric characteristics of the road, driver's gender, and lighting conditions, respectively. In other words, after the construction of BRT lines, the priority and ranking of the variables influencing the severity of accidents have not been changed. Unfortunately, the lighting conditions of this route all the time was one of the concerns of the citizens, and the municipality has always been reluctant to implement an appropriate lighting system for this street. Also, driving culture is always one of the main concerns of Iran and particularly the city of Rasht, which is why gender is one of the top rankings in this route.

Table 2: Mean rank of the Friedman test for accidents

\begin{tabular}{|c|c|c|c|c|c|c|}
\hline \multirow{2}{*}{ Independent variables } & \multicolumn{2}{|c|}{2016} & \multicolumn{2}{c|}{2017} & \multicolumn{2}{c|}{2018} \\
\cline { 2 - 7 } & Average & Rank & Average & Rank & Average & Rank \\
\hline Road geometric characteristics & 11.31 & 1 & 11.11 & 1 & 11.58 & 1 \\
\hline Driver's gender & 11.01 & 2 & 10.81 & 2 & 11.56 & 2 \\
\hline Lighting conditions & 10.81 & 3 & 10.55 & 3 & 11.28 & 3 \\
\hline Collision type & 10.64 & 4 & 10.28 & 4 & 11.14 & 4 \\
\hline Day of the accident & 10.28 & 5 & 10.07 & 5 & 9.22 & 7 \\
\hline Driver's age & 10.15 & 6 & 9.75 & 6 & 9.06 & 8 \\
\hline Accident time & 9.91 & 7 & 9.66 & 7 & 9.97 & 5 \\
\hline The main cause & 9.18 & 8 & 9.42 & 8 & 9.23 & 6 \\
\hline Season of the accident & 6.95 & 9 & 7.36 & 9 & 7.99 & 9 \\
\hline Collision with VPSM & 5.77 & 10 & 6.24 & 10 & 5.42 & 10 \\
\hline Weather conditions & 5.01 & 11 & 5.10 & 11 & 4.63 & 11 \\
\hline At-fault vehicle & 4.23 & 12 & 4.00 & 12 & 3.54 & 13 \\
\hline Road conditions & 3.968 & 13 & 3.89 & 13 & 3.63 & 12 \\
\hline
\end{tabular}

\subsection{Exploratory Factor Analysis (KMO and Bartlett Test)}

Table 3 shows the results of the KMO index and the Bartlett test for the present study. The closer the index is to one, the more appropriate the data is for factor analysis. Furthermore, if the KMO index is less than 0.5, then the factor analysis results are not appropriate for the data in question. Since the KMO index for car accidents in 2017 is less than 0.5 , the factor analysis should be avoided. Also, the significance value of 
Bartlett's test for all cases is less than 5\%, which rejects the assumption of the known correlation matrix.

Table 3: KMO and Bartlett tests

\begin{tabular}{|c|c|c|c|c|}
\hline \multicolumn{2}{|c|}{ Year } & 2016 & 2017 & 2018 \\
\hline \multicolumn{2}{|c|}{ Kaiser-Meyer-Olkin Measure of Sampling Adequacy } & 0.654 & 0.45 & 0.693 \\
\hline \multirow{3}{*}{ Bartlett's Test of Sphericity } & Approx Chi-Square & 750.12 & 320.52 & 405.13 \\
\cline { 2 - 5 } & DF & 76 & 76 & 76 \\
\cline { 2 - 5 } & Significance & 0.000 & 0.000 & 0.000 \\
\hline
\end{tabular}

One of the parts of the factor analysis is related to eigenvalues and determining the factors that remain in the analysis. Factors with an eigenvalue of less than one are deleted from the analysis. Table (4) show the eigenvalues of Imam BRT accidents.

Table 4: Eigenvalues of vehicle accidents in 2016 (before the construction of the BRT line)

\begin{tabular}{|c|c|c|c|c|c|c|c|c|c|}
\hline \multirow[b]{2}{*}{ Component } & \multicolumn{3}{|c|}{ Initial Eigenvalues } & \multicolumn{3}{|c|}{ Extraction of total sum of squares } & \multicolumn{3}{|c|}{ Rotation of total sum of squares } \\
\hline & Total & $\begin{array}{l}\text { Per cent } \\
\text { Variance }\end{array}$ & $\begin{array}{l}\text { Cumulative } \\
\text { percentage }\end{array}$ & Total & $\begin{array}{l}\text { Per cent } \\
\text { Variance }\end{array}$ & $\begin{array}{l}\text { Cumulative } \\
\text { percentage }\end{array}$ & Total & \begin{tabular}{|l|} 
Per cent \\
Varianc
\end{tabular} & $\begin{array}{l}\text { Cumulative } \\
\text { percentage }\end{array}$ \\
\hline \multicolumn{10}{|c|}{ Year: 2016 (before construction of the BRT) } \\
\hline 1 & 1.910 & 14.696 & 14.696 & 1.910 & 14.696 & 14.696 & 1.863 & 14.327 & 14.327 \\
\hline 2 & 1.783 & 13.715 & 28.410 & 1.783 & 13.715 & 28.410 & 1.748 & 13.447 & 27.775 \\
\hline 3 & 1.363 & 10.485 & 38.896 & 1.363 & 10.485 & 38.896 & 1.408 & 10.829 & 38.604 \\
\hline 4 & 1.339 & 10.299 & 49.194 & 1.339 & 10.299 & 49.194 & 1.356 & 10.434 & 49.038 \\
\hline 5 & 1.059 & 8.147 & 57.341 & 1.059 & 8.147 & 57.341 & 1.079 & 8.303 & 57.341 \\
\hline \multicolumn{10}{|c|}{ Year: 2018 (after the construction of the BRT) } \\
\hline 1 & 1.958 & 15.061 & 15.061 & 1.958 & 15.061 & 15.061 & 1.820 & 14.000 & 14.000 \\
\hline 2 & 1.632 & 12.550 & 27.612 & 1.632 & 12.550 & 27.612 & 1.568 & 12.058 & 26.058 \\
\hline 3 & 1.378 & 10.599 & 38.210 & 1.378 & 10.599 & 38.210 & 1.517 & 11.672 & 37.730 \\
\hline 4 & 1.247 & 9.591 & 47.801 & 1.247 & 9.591 & 47.801 & 1.247 & 9.52016 & 47.324 \\
\hline 5 & 1.137 & 8.750 & 56.551 & 1.137 & 8.750 & 56.551 & 1.200 & 9.227 & 56.551 \\
\hline
\end{tabular}

According to table 4 , factors one to five have an eigenvalue more than one and remain in the analysis. Therefore, table 5 represent rotated component matrices, which include the factor loadings of each variable in the remaining factors after the rotation. The higher the absolute value of these coefficients in each row, the factor plays a more significant role in the overall variation of the variable.

Table 5. Rotated component matrix for accidents in 2016 (before the construction of the BRT)

\begin{tabular}{|c|c|c|c|c|c|}
\hline \multicolumn{7}{|c|}{ Year: 2016 (before construction of the BRT) } \\
\hline Variable name & 1 & 2 & 3 & 4 & 5 \\
\hline Accident time & -0.171 & -0.118 & 0.816 & -0.030 & 0.020 \\
\hline Season of the accident & 0.529 & 0.086 & 0.073 & 0.340 & 0.361 \\
\hline Day of the accident & -0.119 & 0.020 & 0.079 & 0.030 & 0.871 \\
\hline Road conditions & 0.847 & -0.005 & -0.012 & 0.004 & -0.003 \\
\hline Road geometric characteristics & 0.205 & -0.033 & -0.120 & -0.140 & 0.312 \\
\hline Lighting conditions & 0.12017 & 0.035 & 0.832 & 0.005 & -0.028 \\
\hline Collision with VPSM & 0.077 & 0.859 & 0.026 & 0.081 & -0.013 \\
\hline At-fault vehicle & -0.128 & 0.101 & -0.107 & 0.668 & -0.127 \\
\hline Driver's age & -0.028 & -0.109 & -0.015 & 0.654 & 0.147 \\
\hline Driver's gender & -0.135 & 0.028 & -0.075 & -0.545 & 0.085 \\
\hline Collision type & -0.003 & 0.872 & -0.043 & 0.055 & -0.142 \\
\hline Weather conditions & 0.834 & -0.026 & 0.020 & -0.066 & -0.062 \\
\hline The main cause & -0.069 & 0.450 & -0.065 & -0.187 & 0.151 \\
\hline
\end{tabular}




\begin{tabular}{|c|c|c|c|c|c|}
\hline Year: 2018 (after the construction of the BRT) \\
\hline Accident time & -0.490 & 0.7040 & 0.0210 & -0.1580 & 0.0480 \\
\hline Season of the accident & 0.064 & -0.2780 & 0.0220 & 0.7750 & 0.0450 \\
\hline Day of the accident & -0.0630 & 0.3840 & -0.1930 & 0.4740 & 0.0760 \\
\hline Road conditions & 0.0750 & 0.0570 & 0.8250 & 0.1400 & -0.0140 \\
\hline Road geometric characteristics & 0.3610 & 0.2090 & 0.0200 & 0.3120 & 0.1 \\
\hline Lighting conditions & 0.0920 & 0.7840 & 0.0810 & -0.0050 & -0.0520 \\
\hline Collision with VPSM & 0.8660 & 0.0840 & -0.0660 & 0.0140 & -0.0450 \\
\hline At-fault vehicle & 0.1960 & 0.0530 & 0.0830 & 0.0920 & 0.7800 \\
\hline Driver's age & -0.1930 & -0.2530 & -0.2160 & -0.3860 & 0.5920 \\
\hline Driver's gender & 0.2760 & -0.3060 & -0.2090 & -0.2520 & -0.4380 \\
\hline Collision type & 0.7830 & 0.0010 & 0.0590 & -0.0420 & -0.0800 \\
\hline Weather conditions & 0.0450 & 0.0240 & 0.8150 & -0.2250 & 0.0750 \\
\hline The main cause & 0.3850 & -0.1280 & 0.1460 & 0.0830 & 0.0011 \\
\hline
\end{tabular}

According to factor analysis on the 13 variables influencing the accident of Imam Street, in 2016 (before construction of BRT line), five factors are identified as prime factors. The factor analysis shows that collision with VPSM, collision type and the main cause variables are considered as the first factor. Also, the variables of road conditions and weather conditions are considered as the second factor. Moreover, accident time and lighting conditions fall under the heading of the third factor. Additionally, at-fault vehicle, age of driver and driver's gender are as the fourth factor. Finally, day of the accident and road geometric characteristics are considered as the fifth factor.

In 2018 (after the construction of the BRT line), five factors are identified as the prime factors. The factor analysis shows that the variables of road geometric characteristics, lighting conditions, collision type, and the main cause are the first factor. Accident time and lighting conditions are the second factor, and road conditions and weather conditions are the third factor. Moreover, accident time and season of the accident are considered as the fourth factor, at-fault vehicle, driver's age and driver's gender are as the fifth factor. It is noteworthy that it was found that road geometric characteristic (accidents along the route or at intersecting points) was one of the important factors after the construction of the BRT line 1 of Rasht.

\subsection{Logit Model of Accidents in Rasht}

In order to model the severity of the BRT line 1 (Imam line) accidents, 13 independent variables along with 1 dependent variable were used. The dependent variable, or the severity of the accidents, was classified into three types of accidents, property damage, injury and fatal accidents. Due to the small number of fatal accidents ( 1 case per year), this kind of accident was assumed to be the same as injury accidents. The independent variables include at-fault vehicle type, the main cause, collision type, driver's age, driver's gender, accident time, road conditions, and so on. In order to build the logit model, enter, backward or forward methods can be used. The point is which of the above methods can provide a better model for the accidents.

For this purpose, the accuracy percentage is considered. The accuracy percentage criterion indicates how much the model's prediction is accurate. The higher the accuracy percentage for the model, the higher the model's capability to predict accidents. All methods are used to enter data into the logit equation. Each of them, which has higher accuracy in predicting the number of accidents, is recognised as the preferred method. Table (6) summarises logit models in enter, forward and backward methods. The criterion for determining the best model is the accuracy of its prediction, as mentioned before. 
Hence, the backward method with the highest accuracy among all cases is selected as the best method for the logit model building of the accident severity of Imam Street.

Table 6: Summary of accidents severity models for Imam Street

\begin{tabular}{|c|c|c|c|}
\hline $\begin{array}{c}\text { Logit regression } \\
\text { method }\end{array}$ & $\begin{array}{c}\text { Accidents of vehicles } \\
(2016)\end{array}$ & $\begin{array}{c}\text { Accidents of vehicles } \\
(2017)\end{array}$ & $\begin{array}{c}\text { Accidents of vehicles } \\
(2018)\end{array}$ \\
\hline Enter & 65.4 & 61.52 & 73.23 \\
\hline Forward & 77.3 & 73.6 & 80.5 \\
\hline Backward & 79.1 & 78.5 & 84.4 \\
\hline
\end{tabular}

As explained, the model obtained through the backward method was chosen as the best model due to the higher accuracy in predicting accidents. Hence, a better description of the model is brought in this section. The chi-square statistic is based on the determination of the extent of the effect of independent variables on the dependent variable and, in general, fitting the whole model. It is comparable to the F statistic in ordinary regression analysis. Table 7 shows the coefficients of the backward model for vehicle accidents for the years 2016, 2017 and 2018. According to this table, the chi-square of the model demonstrates whether the independent variables exert an influence over the dependent variable or not. As can be seen, in each of the models, a chi-square from the model is seen that its Sig. is zero. Therefore, independent variables influence the dependent variable, indicating that fit is appropriate.

Table 7. Backward model coefficients of 2016 (before the BRT line construction)

\begin{tabular}{|c|c|c|c|c|}
\hline & & Chi-square & $D F$ & Sig. \\
\hline & & re: 2016 (befo & onst & \\
\hline & Step & -0.981 & 1 & 0.322 \\
\hline Step 15 & Block & 261.545 & 25 & 0.000 \\
\hline & Model & 261.545 & 25 & 0.000 \\
\hline & & ar: 2017 (aft & nstr & \\
\hline & Step & -2.208 & 1 & 0.137 \\
\hline Step 13 & Block & 92.263 & 13 & 0.000 \\
\hline & Model & 92.263 & 13 & 0.000 \\
\hline & & ar: 2018 (aft & nstr & \\
\hline Step 11 & Step & 3.641 & 1 & 0.056 \\
\hline & Block & 195.443 & 21 & 0.000 \\
\hline & Model & 195.443 & 21 & 0.000 \\
\hline
\end{tabular}

By selecting the backward method and entering all the variables selected in the modelling process, after the completion of several steps, the final model of this method was obtained. The variables used in the model, the results of the Wald test and the final logit model, have reflected in table 8 . The Wald test examines the significance of the variables entered in the regression equation and is comparable to the $t$ statistic in the ordinary regression. Based on this table, the logit model can be presented for different years in this way. Positive coefficients of independent variables indicate their positive relationship with the severity of accidents and negative coefficients, indicating their negative relationship with the severity of accidents. 
Table 8. Variables of the severity of vehicle accident logit model in 2016, 2017, and 2018

\begin{tabular}{|c|c|c|c|c|c|}
\hline \multicolumn{6}{|c|}{ Year:2016 } \\
\hline Predictive variables & $(\beta)$ & $\begin{array}{l}\text { Standard } \\
\text { deviation }\end{array}$ & $\begin{array}{c}\text { Wald } \\
\text { statistic }\end{array}$ & Significance & Odds ratio \\
\hline Accident time: $12-18$ & 0.738 & 0.312 & 5.602 & 0.018 & 2.092 \\
\hline Season of the accident : autumn & 0.779 & 0.361 & 4.647 & 0.031 & 2.179 \\
\hline Day of the accident : Tuesday & -0.894 & 0.360 & 6.175 & 0.013 & 0.409 \\
\hline Day of the accident : Wednesday & -0.756 & 0.333 & 5.162 & 0.023 & 0.470 \\
\hline Road geometric characteristics: straight route & 1.774 & 0.849 & 4.363 & 0.037 & 5.894 \\
\hline Collision with light vehicles & 3.568 & 0.572 & 38.901 & 0.000 & 35.437 \\
\hline Lighting conditions : daylight & -2.915 & 0.628 & 21.554 & 0.000 & 0.054 \\
\hline Constant & -7.284 & 0.120 & 0.335 & 1.000 & 0.001 \\
\hline \multicolumn{6}{|c|}{ Year:2017 } \\
\hline Accident time : $6-12$ & 2.372 & 0.333 & 5.162 & 0.000 & 1.643 \\
\hline Accident time : $12-18$ & 1.529 & 0.849 & 4.363 & 0.0423 & 3.795 \\
\hline Collision with pedestrian & -2.512 & 0.572 & 0.335 & 0.02 & 21.751 \\
\hline Collision with separator fence & -1.041 & 0.575 & 5.602 & 0.050 & 0.731 \\
\hline Collision with another vehicle & -1.523 & 0.345 & 3.857 & 0.023 & 0.0022 \\
\hline Collision type: head-on & -1.451 & 0.312 & 1.632 & 0.000 & 7.211 \\
\hline Day of the accident: Saturday & -0.711 & 0.361 & 4.647 & 0.000 & 1.351 \\
\hline The main cause : lack of attention & -3.218 & 0.360 & 6.175 & 0.000 & 1.032 \\
\hline The main cause : & -1.754 & 0.434 & 38.901 & 0.013 & 1.794 \\
\hline Road geometric characteristics : intersection & 0.999 & 0.189 & & 0.023 & 0.133 \\
\hline Constant & 146.73 & 3.819 & 22.988 & 0.000 & 0.463 \\
\hline \multicolumn{6}{|c|}{ Year: 2018} \\
\hline Accident time : $6-12$ & 1.642 & 0.342 & 8.453 & 0.031 & 5.454 \\
\hline Collision with pedestrian & -1.464 & 0.134 & 2.433 & 0.00 & 14.353 \\
\hline Day of the accident: Saturday & -0.928 & 0.468 & 1.163 & 0.004 & 2.176 \\
\hline The main cause : lack of attention & - & 0.157 & 2.976 & 0.012 & 2.085 \\
\hline Road geometric characteristics : intersection & 0.731 & 0.853 & 7.234 & 0.000 & 0.156 \\
\hline Constant & 83.754 & 0.674 & 12.432 & 0.041 & 1.936 \\
\hline
\end{tabular}

According to Table 8, before the construction of the BRT line in Rasht in 2016, variables of the accident time: 12-18, season of the accident: autumn and day of the accident: Tuesday and Wednesday, and collision with light vehicles, were effective variables on the severity of accidents. However, in 2017 and 2018, after the construction of the BRT line, accidents were influenced by the time: 6-12 rather than 12-18. Also, day of the accident has been changed to Saturday (in Iran, Saturday is the first day of the week and Friday is a day of rest). Perhaps the reason for this shift in hours and days is that more people use Imam Street to go to work and school at these times rather than other times. Moreover, collision with light vehicles after the construction of the BRT line has been changed into collisions with pedestrian and separator fence.

Additionally, accidents were more at intersections in 2017 and 2018 and mainly because of failure to yield the right-of-way. After the construction of the special line, the day of the accident has changed to Saturday, the type of collision to collision with the pedestrian and the main cause to the lack of attention and failure to yield the right-ofway. Therefore, it is recommended that Rasht police use more human resources or video surveillance (smart violation recording) in the first days of the week (Saturday) than other days. Also, to observe the right-of-way, police presence at the intersections should be more than other parts of the special line. 


\subsection{Identify dangerous locations}

In order to investigate the dangerous locations where the severity of accidents which occurred is higher than other locations, by using the Relative Severity Index (RSI), these locations were identified more precisely. In this criterion, the classified model of road safety index is defined based on three indexes related to the severity of accidents. The road safety index in this method is defined, by considering the Equivalent Property Damage Only (EPDO) recommended by the world road association (PIARC), the Severity Index (SI), which indicates the ratio of the type to the total number of accidents is recommended by the University Transportation Center of Alabama (UTCA). The severity index (IG) recommended by the Portuguese road authorities.

The IG parameter determines the safety index only based on the relative level of the accident severity and is defined by the Portuguese road authorities in the form of equation (4), in which IG severity index, $T_{A}$ number of fatal accidents, $T_{B}$ number of severe injury accidents and $\mathrm{T}_{\mathrm{C}}$ number of damage accidents. In order to calculate other indexes (EPDO) and (SI), respectively, equations (5) and (6) are utilised (Ziari et al., 2017).

$\mathrm{IG}=\left(100 \times \mathrm{T}_{\mathrm{A}}+10 \times \mathrm{T}_{\mathrm{B}}+3 \times \mathrm{T}_{\mathrm{C}}\right)$

EPDO $=\left(5 \times \mathrm{T}_{\mathrm{A}}+3 \times \mathrm{T}_{\mathrm{B}}+1 \times \mathrm{T}_{\mathrm{C}}\right)$

$\mathrm{SI}=\frac{\text { Number of fatal accidents }}{\text { Total number of accidents }}$

The Analytic Hierarchy Process (AHP) has been used to obtain the weight of each index based on the pairwise comparison. Thus, the RSI is defined according to equation (7). In this equation, the RSI is relative severity index, $\mathrm{f}$ (IG), g (EPDO) and $\mathrm{h}$ (SI), respectively, the normalised indexes of these three indexes: accident severity, equivalent property damage only, and cost. Moreover, $\mathrm{W}_{\mathrm{IG}}, \mathrm{W}_{\mathrm{SI}}$ and $\mathrm{W}_{\mathrm{EPDO}}$ are the corresponding weights of each index.

$\mathrm{RSI}=\mathrm{f}(\mathrm{IG}) \times \mathrm{W}_{\mathrm{IG}}+\mathrm{g}($ EPDO $) \times \mathrm{W}_{\mathrm{EPDO}}+\mathrm{h}(\mathrm{SI}) \times \mathrm{W}_{\mathrm{SI}}$

In this methodology, firstly, after preparing questionnaires, 35 experts in traffic safety were surveyed for multi-criteria decision making and hierarchical analysis. The weights of each index were obtained for use in the RSI index in Table 9.

Table 9. The weights of the indexes used to calculate the RSI index

\begin{tabular}{|c|c|c|c|}
\hline Index & $E P D O$ & $I G$ & $S I$ \\
\hline Weight & 0.374 & 0.482 & 0.144 \\
\hline
\end{tabular}

As a result, first, a hierarchical structure of the AHP was formed, then the safety indices of each location were compared by using the pairwise comparison. Finally, their importance was measured in relation to one another. The dangerous sections of the studied BRT line were determined according to Figure 8. Also, the results of the RSI index were obtained according to Table 10 . 
Table 10. Results of accident severity in different locations of the studied route

\begin{tabular}{|c|c|c|c|c|c|c|c|}
\hline \multicolumn{8}{|c|}{ Year: 2016} \\
\hline Location & $\begin{array}{c}\text { Number of } \\
\text { injury accidents }\end{array}$ & $\begin{array}{c}\text { Number of } \\
\text { fatal accidents }\end{array}$ & $\begin{array}{l}\text { Number of property } \\
\text { damage only accidents }\end{array}$ & $(I G)$ & $(E P D O)$ & (SI) & (RSI) \\
\hline Meli Bank & 7 & 0 & 2 & 76 & 23 & 0 & 0.45 \\
\hline Razi & 10 & 0 & 0 & 100 & 30 & 0 & 0.59 \\
\hline Mikael & 3 & 0 & 1 & 33 & 10 & 0 & 0.20 \\
\hline Saderat & 8 & 0 & 2 & 86 & 26 & 0 & 0.51 \\
\hline Farhang & 8 & 1 & 0 & 180 & 29 & 0.01 & 0.98 \\
\hline Taban & 4 & 0 & 1 & 43 & 13 & 0 & 0.26 \\
\hline Manzarea & 13 & 0 & 0 & 130 & 39 & 0 & 0.77 \\
\hline Mosalla & 6 & 0 & 0 & 60 & 18 & 0 & 0.36 \\
\hline \multicolumn{8}{|c|}{ Year: 2017} \\
\hline Meli Bank & 1 & 0 & 1 & 13 & 4 & 0 & 0.08 \\
\hline Razi & 12 & 0 & 3 & 129 & 39 & 0 & 0.77 \\
\hline Mikael & 4 & 0 & 0 & 40 & 12 & 0 & 0.24 \\
\hline Saderat & 6 & 0 & 2 & 66 & 20 & 0 & 0.39 \\
\hline Farhang & 3 & 0 & 1 & 33 & 10 & 0 & 0.20 \\
\hline Taban & 1 & 0 & 0 & 10 & 3 & 0 & 0.06 \\
\hline Manzarea & 8 & 1 & 1 & 183 & 30 & 0.01 & 0.99 \\
\hline Mosalla & 3 & 0 & 1 & 33 & 10 & 0 & 0.20 \\
\hline \multicolumn{8}{|c|}{ Year: 2018} \\
\hline Meli Bank & 2 & 0 & 1 & 23 & 7 & 0 & 0.14 \\
\hline Razi & 8 & 0 & 1 & 83 & 25 & 0 & 0.49 \\
\hline Mikael & 3 & 0 & 3 & 39 & 12 & 0 & 0.23 \\
\hline Saderat & 0 & 0 & 0 & 0 & 0 & 0 & 0.00 \\
\hline Farhang & 4 & 0 & 1 & 43 & 13 & 0 & 0.26 \\
\hline Taban & 2 & 0 & 0 & 20 & 6 & 0 & 0.12 \\
\hline Manzarea & 10 & 0 & 5 & 115 & 35 & 0 & 0.69 \\
\hline Mosalla & 4 & 0 & 1 & 43 & 13 & 0 & 26 \\
\hline
\end{tabular}

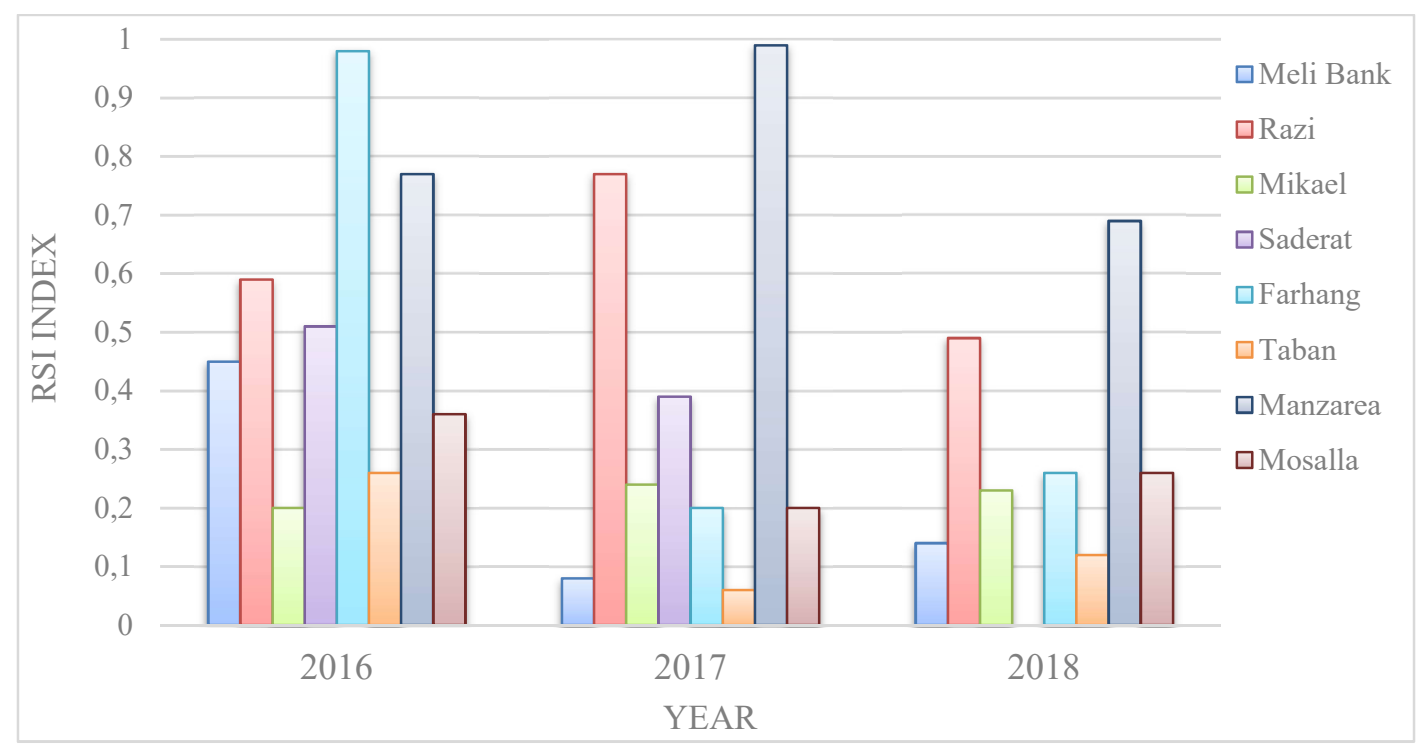

Figure 8: Dangerous locations according to the RSI index by year

According to Figure 8, as well as table 10, almost all of the length of Imam street in 2016 (except the intersection of the Mikael and Taban, which are safe locations in every three years), had RSI indexes bigger than 0.3. However, after the construction of BRT in 2017, the number of accidents in Imam Street reduced. However, accidents have concentrated in some specific locations. The number of accidents reduced in 2018 in 
comparison with 2016 and 2017. So it can be observed in 2018, just two locations (Manzarea and Razi) had RSI indexes bigger than 0.3 . This reduction perhaps was due to blocking some open sections along the BRT separator fence due to the existence of specific uses around the street as well as accustoming citizens to this system.

Nevertheless, with consideration to the accident risk of Manzarea and Razi locations in every three years 2016, 2017 and 2018, it is suggested that the BRT open separator fence section be closed at these locations. This action prevents the cross of pedestrians in these sections. In these two sections, there is a famous restaurant and also a clinical diagnostic lab, and owners of these two always prevent the blocking open sections by Rasht municipality.

\section{Conclusion}

In this study, by analysing accident data of Imam Street of Rasht city, the effects of different variables on the severity of this street accidents before the construction of BRT (2016) and after its construction (2017 and 2018) were investigated.

Regarding the results of the frequency of the variables, it was found that the construction of the BRT line 1 has reduced the number of accidents in 2017 and 2018 compared to 2016. The reason can be a reduction of passenger car use and, consequently, a decline in traffic volume, yet some new accidents types have emerged, for example, collision with the BRT separator fence. However, after accustoming of drivers to the BRT line, these types of accidents have gradually declined. Another negative point was the increase in the number of pedestrian accidents, especially at the intersection, which is why it is suggested that police should pay more attention to drivers who exceed speed limits and are careless with pedestrian crosswalks and pedestrian crossing green light. Before the construction of the BRT, accidents occurred at all points along the route, but after its construction, accidents were concentrated mostly at intersections, which could help to pinpoint the accidental points more accurately and correct them.

The ranking of the influential variables on the severity of accidents has not changed by the construction of BRT lines. However, the geometric design of road (occurrence of accidents along the route or at intersections) has become one of the most important factors after the construction of BRT lines.

Logit modelling of independent variables on the accident severity variable indicated that the accident hours 12 to 18, and the day of Tuesday and Wednesday, and collision with a passenger car, were the influential independent variables in 2016 (before construction). But after the construction of the BRT, the day of accidents in 2017 and 2018 changed into the beginning of the week, and the type of collision altered to the collision with pedestrian because of lack of attention and failure to yield the right-of-way. 


\section{References}

Bargegol, I., Ghorbanzadeh, M., Ghasedi, M. and Rastbod, M., 2017, October. Evaluation of Effective Factors on Travel Time in Optimization of Bus Stops Placement Using Genetic Algorithm. In IOP Conference Series: Materials Science and Engineering (Vol. 245, No. 4, p. 042002). IOP Publishing.

Raju, N., Chepuri, A., Arkatkar, S., \& Joshi, G., 2020, A Simulation Study for Improving the Traffic Flow Efficiency of an Intersection Coupled with BRT. European Transport/Trasporti Europei, Issue $\mathrm{n}^{\circ} 75$.

Vecino-Ortiz, A.I. and Hyder, A.A., 2015. Road safety effects of bus rapid transit (BRT) systems: a call for evidence. Journal of urban health, 92(5), pp.940-946.

Scorcia, H. and Munoz-Raskin, R., 2019. Why South African cities are different? Comparing Johannesburg's Rea Vaya bus rapid transit system with its Latin American siblings. Case Studies on Transport Policy, 7(2), pp.395-403.

Gómez, F. and Bocarejo, J.P., 2015. Accident prediction models for bus rapid transit systems: generalized linear models compared with a neural network. Transportation research record, 2512(1), pp.38-45.

Yoon, S., Kho, S.Y. and Kim, D.K., 2017. Effect of regional characteristics on injury severity in local bus crashes: use of hierarchical ordered model. Transportation research record, 2647(1), pp.1-8.

Goh, K.C.K., Currie, G., Sarvi, M. and Logan, D., 2013. Road safety benefits from bus priority: an empirical study. Transportation research record, 2352(1), pp.41-49.

Song, Y. and Noyce, D., 2018. Assessing Effects of Transit Signal Priority on Traffic Safety: Empirical Bayes Before-After Study using King County, Washington, Data. Transportation research record, 2672(8), pp.10-18.

Wenfang, T., Yuqi, M., Xiyuan, Z. and Rujing, G., 2018, November. Traffic Accident Analysis With Or Without Bus Priority. In IOP Conference Series: Earth and Environmental Science (Vol. 189, No. 6, p. 062024). IOP Publishing.

Goh, K.C.K., Currie, G., Sarvi, M. and Logan, D., 2014. Bus accident analysis of routes with/without bus priority. Accident Analysis \& Prevention, 65, pp.18-27.

Goh, K.C., Currie, G., Sarvi, M. and Logan, D., 2014. Experimental microsimulation modeling of road safety impacts of bus priority. Transportation research record, 2402(1), pp.9-18.

Morency, P., Strauss, J., Pépin, F., Tessier, F. and Grondines, J., 2018. Traveling by bus instead of car on urban major roads: safety benefits for vehicle occupants, pedestrians, and cyclists. Journal of urban health, 95(2), pp.196-207.

Santos-Reyes, J. and Ávalos-Bravo, V., 2014. A preliminary analysis of two Bus Rapid Transit accidents in Mexico City. Procedia Engineering, 84, pp.624-633.

Kim, S., Choi, J., Kim, M. and Kim, S., 2012. Determination of accident modification factors for the median bus lanes on urban arterials. International journal of urban sciences, 16(1), pp.99-113.

Bocarejo, J.P., Velasquez, J.M., Díaz, C.A. and Tafur, L.E., 2012. Impact of bus rapid transit systems on road safety: lessons from Bogotá, Colombia. Transportation research record, 2317(1), pp.1-7.

Calvo, J.A.P., 2017. The effects of the bus rapid transit infrastructure on the property values in Colombia. Travel Behaviour and Society, 6, pp.90-99. 
Bargegol, I., Gilani, V. N. M., Ghasedi, M., \& Ghorbanzadeh, M., 2016, Delay Modeling of Un-signalized Roundabouts Using Neural Network and Regression. Computational Research Progress in Applied Science \& Engineering (CRPASE), 2(1).

Gilani, V. N. M., Ghasedi, M., Ghorbanzadeh, M., \& Samet, M. J., 2017, October, Estimation Delay Variation and Probability of Occurrence of Different Level of Services Based on Random Variations of Vehicles Entering Signalized Intersections. IOP Conference Series: Materials Science and Engineering (Vol. 245, No. 4, p. 042023). IOP Publishing.

Bargegol, I, Gilani, V. N. M., 2017. Modeling of Urban Accidents Using Logistic Regression. The 1th National Conference on Highway and Transportation. University of Guilan, Iran.

Thompson, B., 2004. Exploratory and confirmatory factor analysis: Understanding concepts and applications. Washington, DC, pp.10694-000.

Chatfield, M. and Mander, A., 2009. The Skillings-Mack test (Friedman test when there are missing data). The Stata Journal, 9(2), pp.299-305.

Behbahani, H., Samet, M.J., Gilani, V.N.M. and Amini, A., 2017, October. Determining of the Parking Manoeuvre and the Taxi Blockage Adjustment Factor for the Saturation Flow Rate at the Outlet Legs of Signalized Intersections: Case Study from Rasht City (Iran). IOP Conference Series: Materials Science and Engineering (Vol. 245, No. 4, p. 042017). IOP Publishing.

Bargegol, I., Amlashi, A. T., \& Gilani, V. N. M., 2016, Estimation the saturation flow rate at far-side and nearside legs of signalized intersections-case study: rasht city. Procedia engineering, 161, 226-234.

Ziari, H., Amini, A., Saadatjoo, A., Hosseini, S.M. and Gilani, V.N.M., 2017. A Prioritization Model for the Immunization of Accident Prone Using Multi-criteria Decision Methods and Fuzzy Hierarchy Algorithm. Computational Research Progress in Applied Science \& Engineering (CRPASE), 3(3). 